\title{
A Comparative Study of Thiel Soft-embalmed and Formalin Preserved Cadavers for Anatomy Dissection
}

\author{
Pio Renato F. Villacorta, ${ }^{1}$ Harivelle Charmaine T. Hernando, ${ }^{1}$ Abdel Jeffri A. Abdulla ${ }^{1}$ and Jupiter Kelly H. Barroa ${ }^{1}$
}

${ }^{1}$ Department of Anatomy, College of Medicine, University of the Philippines Manila

\begin{abstract}
Background and Objective. Cadavers are the main teaching and learning tools utilized by faculty and students of Gross Anatomy. The conventional procedure of using formalin to preserve cadavers has its limited benefit due to its obnoxious odor, darkened color, indistinguishable small structures, rigid joints, with friable organs and tissues. Using the Thiel Method, cadavers are known to have: life-like presentation, a high degree of suppleness, natural mobilization of various body parts with tolerable odor, natural color, and antimicrobial and antifungal efficacy. The aim of this study was to compare the Thiel soft-embalmed cadaver and the formalin-preserved cadaver for use in Gross Anatomy dissection.
\end{abstract}

Materials and Method. Six formalin-preserved cadavers were compared with six Thiel soft-embalmed ones and were evaluated by 160 first year medical students and 10 faculty members of Gross Anatomy from the University of the Philippines College of Medicine using a visual analogue scale that evaluated the cadaver's presenting color. A Likert scale was utilized to assess the skin and muscle texture, blood vessel integrity, odor, joint flexibility, and state of cadaver preservation. Their perceptions on the ease of the dissection process, distensibility, and differentiation of structures were also elicited through a questionnaire checklist.

Results. Results show that the Thiel Method-preserved cadavers were rated higher compared to the formalinpreserved cadavers in terms of: 1) presenting color; 2) tolerable odor; 3) skin and muscle texture; 4) blood vessel integrity; 5) joint flexibility; and 6) state of cadaver preservation after 1 year. However, the ease of the dissection process, the distensibility of structures, and the differentiation of the various structures were easily managed in the formalin-preserved cadavers while the feasibility of practicing laparoscopy, endoscopy, and intubation were seen in the Thiel soft-embalmed cadavers. Results validate the claims of previous studies on the advantages presented in using the Thiel Method.

Conclusion. Cadavers preserved utilizing the Thiel Method are life-like and can be used for Gross Anatomy dissection. The data gathered support the feasibility of using them also in research and training.

Key Words: Thiel cadaver, formalin-preserved cadaver, gross anatomy

\section{INTRODUCTION}

Corresponding author: Pio Renato F. Villacorta, MD Department of Anatomy

College of Medicine

University of the Philippines Manila

547 Pedro Gil Street, Ermita, Manila 1000, Philippines

Telephone: +6325264194

Email: piovillacorta@yahoo.com

\section{Significance of the Study}

Gross Anatomy is a fundamental basic science subject in medical school. Through Gross Anatomy, medical students get a first impression about the structure of the normal human body, which is the basis for understanding physiologic, pathologic, and clinical scenarios. With dissection as the main strategy, there is a need to provide students with realistic representations of the human body through fixed cadavers bearing organs and tissues that retain the natural human color, texture, and flexibility with bearable odor. ${ }^{12}$

Cadavers fixed by conventional procedures using formalin for conservation are of limited use due to the profound changes in color, strength, and texture of organs 
and tissues, as well as offensive odor. Students therefore have to endure the obnoxious smell and toxic effects of formalin while dissecting the structure they need to learn. ${ }^{2}$

The new Thiel embalming technique results in wellpreserved organs and tissues. The articular joints remain freely movable and the peritoneal cavity can be inflated for a realistic representation. The color of the organs is very similar to the in vivo condition; only, no bleeding occurs. Lastly, dissection can be done in a conducive environment devoid of the repugnant odor of formalin and the gruesome appearance of formalin-preserved cadavers. ${ }^{19}$

The aim of this study was to compare the Thiel soft-embalmed cadaver with the conventionally-fixed cadaver using formalin for dissection purposes of Gross Anatomy students. It also assessed the outcome of cadaver preservation using the Thiel method and if proven suitable and superior to the conventional, formalin-based method, this would promote an atmosphere conducive to dissection and learning, and promote students' safety. The hazardous effects of formalin to students, faculty and laboratory aides could therefore be avoided.

\section{REVIEW OF LITERATURE}

\section{Historical Perspective}

Embalming or cadaver preservation dates back to ancient Egypt, where priests mummified bodies for the afterlife. The same techniques were used later by anatomists of the Middle Ages and Renaissance, who dissected bodies for anatomical and pathological study. ${ }^{22}$

Not much has changed in the past 150 years. While the chemical make-up of modern embalming fluid varies, it typically includes formaldehyde, a substance with strong antibacterial, antifungal and antiviral properties. It kills pathogens and arrests decay caused by bacteria. However, the drawbacks of formaldehyde include: there is drying out and hardening of tissues; the compound is toxic, requiring the use of masks and protective gear (for those working with it); and when in contact with a pregnant female, it can cause birth defects. ${ }^{3}$

Most cadavers embalmed for dissection are used within six months to a year, before starting to decay. Using the Thiel Method, cadavers can last up to five years. In the 1960s, Austrian anatomist, Dr. Walter Thiel, started with cuts of meat and using a salt-based process, perfected a method that resulted in cadavers with the look and feel of living people. When Thiel retired, the technique was further refined by Dr. Friedrich Anderhuber. ${ }^{22,23}$

Instead of injecting a formaldehyde-based solution through the arterial system, Thiel's method uses a mixture of salt compounds with low levels of formaldehyde and formalin. It does not distort, dehydrate, or discolor the body's tissues the way traditional embalming does. The technique mixes two solutions for injection into the body, adjusted to the weight of the cadaver. The Virginia State
Anatomical Program in Richmond, Virginia, USA modified the process by skipping the step of submerging bodies in an expansive liquid after embalming. ${ }^{22}$

\section{Modes of Preservation}

There are 2 means of preserving the dead body: natural means and artificial means of preservation. Natural means of preservation include: freezing, desiccation/exsiccation either by dry cold or dry heat, and the nature of the soil. Artificial means of preservation comprise the application of simple heat or cold, powders such as sawdust bed mixed with zinc sulphate, evisceration combined with immersion, drying, local incision and immersions, arterial injections, and cavity injections. Furthermore, simple immersion in alcohol, brine, or other preservative solutions, and sole arterial injection which can be combined with cavity treatment and/ or immersion are used. ${ }^{3}$

\section{Body Preservation Methods}

In anatomical embalming, unlike that for funerals, the focus is on long-lasting preservation of tissues rather than the maintenance of physical appearance. Embalmed cadavers and fresh-frozen tissues are used in education, training and research. Embalmed bodies have the advantage of carrying minimal risk of infection and being suitable for prolonged use. Dissection in Gross Anatomy is done on the complete body providing a realistic experience. However, depending on the type of embalming, changes in mobility, color, or tissue handling may occur. ${ }^{16,18}$

Fresh-frozen bodies tend to be more realistic-looking and flexible. However, their disadvantages include the short period available before deterioration, the possibility of inadequate thawing, and if separated body parts are used, the need for these to be clamped in place for demonstration of surgical procedures.

The formalin-embalmed cadavers are therefore used for long-lasting dissection courses since they are durable but stiff. The fresh-frozen cadavers are preferred for surgical training. However, a soft-fix preservation method, developed by Thiel in the $1990 \mathrm{~s}^{3,8}$ now produces cadavers that are both flexible and preserved for long term and suitable for most current activities while additionally providing new opportunities for learning. Thiel soft-embalmed cadavers are much more life-like than formalin-embalmed cadavers. There is good joint flexibility and tissue color and planes are well-retained. They are preserved for a long term and require minimal care while in use. ${ }^{23}$

\section{Various Studies}

In the study by $\mathrm{Hadie}^{15}$, the need to have a valid and reliable tool in measuring the Anatomy educational environment has been emphasized. Indeed, according to the authors, insufficient Anatomy knowledge leading to errors in identification of anatomical structures has grave implications and repercussions for future practice. Thus, in 
order to achieve optimum Anatomy education environment and to close the gaps in education, measuring the students' perception on Anatomy teaching and learning with the use of cadavers and models simulating the living subject is a pre-requisite for educators.

In another study by Kotze ${ }^{20}$, it has been noted that there is neglect in the emphasis of surface Anatomy during the dissection process with cadavers that are poorly preserved; thus, they recommended the novel use of Ladox Statscan images in depicting the surface anatomy to overcome the struggle with the study of this area, and to use preservative solutions that present tissues, organs, and structures closely resembling the living subject.

The study by $\mathrm{Cuddy}^{5}$, provides empirical evidence on the impact of acquisition and retention of Anatomy knowledge utilizing curricular approach (stand-alone versus integrated) and laboratory experience (dissection versus dissection and prosection) on USMLE scores. The respondents to the survey were 54 USA school directors, providing information on the strategies they use in teaching Anatomy. It was found out that examinees from schools with dissection and prosection experience, performed better in the USMLE Step 2 Clinical Knowledge part compared with the other curricular approach. It was also found out that fixation of the cadavers dissected by the students, employed techniques that preserved the color, texture, and flexibility of the structures being studied.

The invention of new techniques for surgery and interventional radiology demands improved training for on-going specialists. The Anatomical Institutes in Switzerland ${ }^{13}$ support these requirements by establishing hands-on practical training courses by using new procedures for cadaver embalming and model construction. Improvements allow courses to provide students with more realistic simulations of both established and experimental surgical methods. Through these changes, the value of indepth Gross Anatomy teaching is enhanced as a topic of fundamental importance for the post-graduate medical and surgical curriculum. The authors have recommended the use of the Thiel embalming solution for cadavers to come as close as possible to clinical reality, thus getting a first impression about structures of the normal human body, which is the basis for understanding pathologic and clinical problems.

In line with the above study, Kerckaert ${ }^{19}$ also claims that the Endogent Center for Anatomy and Invasive Techniques in Belgium supports the requirements of endoscopic techniques for surgery and interventional radiology by establishing hands-on practical training courses by using new procedures for cadaver embalming. The authors claim that there is limited use for practical surgical courses such as endoscopy with the formalin-preserved cadavers since they are stiff and rigid with non-distensible structures. The new Thiel Method of preserving cadavers has revolutionized the study of Anatomy and gave way to a better way for surgeons to practice on before doing it on their live patients.
In conclusion, they recommend using the Thiel Method in preserving cadavers to enhance understanding and studying of the anatomical structures for better correlation in the clinical sciences.

Da Silva ${ }^{6}$ studied live, anesthetized animals and freshlypreserved animal cadavers for surgical teaching in veterinary school. According to the authors for training to be effective, it is desirable that cadavers simulate as closely as possible the tissue characteristics of live animals. The authors recommended solutions with least formalin since retaining organoleptic characteristics without any undesirable odor provides a safe and healthy learning environment.

A comparison of fresh and Thiel soft-embalmed cadavers according to the suitability for ultrasound-guided regional anesthesia was studied by Benkhadra ${ }^{2}$. Using 16 cadavers ( 8 fresh cadavers and 8 Thiel soft-embalmed cadavers), the authors revealed that the two groups were comparable in terms of sex, age, and BMI. Visibility of the sternocleidomastoid muscle and ease in performing nerve blocks were significantly better with the Thiel group. Thus, the authors recommend the Thiel Method in preserving cadavers for learning and training purposes.

\section{MATERIALS AND METHODS}

Cadavers donated to the UP College of Medicine are most of the time unclaimed remains with no known relatives. They usually come from the Philippine Center for Mental Health. Death certificates accompany every donated body duly signed by in-house physicians. Requirements on the use of remains for scientific purposes are in accordance with Section 15.2 of the IRR of PD 856. ${ }^{27}$ This is strictly followed by the UP College of Medicine Department of Anatomy.

The cadavers chosen for this study were adults with an age range of 17-75 years old, Filipinos, and of either sex (5 males and 7 females).

This study involved 6 cadavers preserved in formalin and 6 cadavers preserved using the Thiel Method. The 12 cadavers were evaluated by 160 medical students and 10 faculty members of Gross Anatomy of the University of the Philippines College of Medicine. A questionnaire was used to determine the following data in 3 categories: 1 ) evaluator's name, position, date of evaluation; 2) cadaver's age, sex, preservation method used, presenting color, texture of skin and muscle, blood vessel integrity, odor, joint flexibility, and state of cadaver preservation; and 3) perceptions of evaluator on ease of dissection process, distensibility of structure, feasibility of practicing procedures on the cadaver, and differentiation of various structures.

The formalin-preserved cadavers were stored in a vat containing roughly 500 liters of $10 \%$ formalin diluted in water. After a year of submersion, the 6 cadavers were lifted from the vat and placed on the dissecting tables for 7 days at room temperature in preparation for the opening of classes. 
On the other hand the Thiel-preserved cadavers utilized the soft embalming protocol being employed at the Virginia State Anatomical Program in Richmond, Virginia, USA. ${ }^{26}$ With some modifications of bleeding the cadaver, the process consists of an arterial pre-injection solution (A) and an arterial injection solution (B) utilizing two separately formulated solutions (A and B) that are later combined with additional chemicals.

The pre-injection arterial solution utilized is a chemical called Calsec (manufactured by Dodge Chemical Company) consisting of one 16 ounce bottle mixed with a half gallon of water. Due to the unavailability of Meta Flow which is the prescribed solution, Calsec was substituted.

The chemicals used for Solution A are: boric acid, mono-ethylene glycol, ammonium nitrate, and potassium nitrate. For Solution B: mono-ethylene glycol and 4-chloro3-methylphenol. Both solutions are mixed together with sodium sulphite, morpholine, formalin, and denatured ethyl alcohol. This final solution constitutes the arterial injection solution.

The volume of the arterial solution is dependent on the weight of the cadaver ( 1 gallon: $30 \mathrm{lbs}$ ). Once the embalming process is completed the cadavers are placed in a cadaver bag, stored in a freezer and allowed to cure for 14 days before it undergoes degloving.

On the first day of Gross Anatomy laboratory for courses OSI 203, OSI 204, OSI 205, and OSI 206, all evaluators went over the 6 formalin-preserved cadavers and the 6 Thielpreserved cadavers to complete the questionnaire pertaining to color, odor, texture and flexibility of joints. Again, on the last day of dissection in Gross Anatomy course OSI 206, all evaluators went over again the 12 cadavers and answered the questions on the preservation status of the cadavers.

It should be noted that after every dissection period, the 6 Thiel-preserved cadavers were placed back in their respective vacuum sealed bags and stored in the freezer. On the other hand, the 6 formalin-preserved cadavers were cleaned of dissection mess and kept covered with petroleum jelly and a sack cloth on the aluminum tables awaiting for the next dissection period. Both are considered routine maintenance procedures for the two cadaver embalming methods.

\section{RESULTS}

All 160 first year medical students and 10 faculty members of the Department of Anatomy, UP College of Medicine participated in the study. Everyone evaluated the twelve cadavers (6 Thiel soft-embalmed and 6 Formalinpreserved) during Gross Anatomy laboratory dissection for the following courses: Organ System Integration 203 which dealt with the skin, muscle and bones; Organ System Integration 204 (OSI 204) which studied the head and neck; OSI 205 which focused on the thorax; and OSI 206 concentrated on the abdomen, urogenital system, pelvis, and perineum.

\section{Demographic characteristics of the cadavers}

The six Thiel soft-embalmed cadavers had an age range of 30 to 65 years while the six formalin-preserved cadavers were aged from 17 to 75 years old. There were 3 males and 3 females in the Thiel-preserved cadavers, while 2 males and 4 females comprised the formalin-preserved cadavers. All twelve cadavers were Filipinos.

\section{Physical characteristics of the cadavers}

Figure 1 shows the questionnaire used to assess the physical characteristics of cadavers. Table 1 shows the results of the assessment of the physical characteristics of the 12 cadavers. From the responses gathered from the questionnaire answered by the participants, the six Thiel soft-embalmed cadavers were assessed with the following characteristics: 1) cadaver color: cream to pale brown; 2) skin texture: smooth, soft, tender; 3) blood vessels and nerves: firm but distensible; 4) muscles: soft and smooth, well-differentiated; 5) odor:

Table 1. Assessment of Physical Characteristics of Thiel and Formalin-Preserved Cadavers

\begin{tabular}{|c|c|c|c|c|c|c|c|c|c|c|}
\hline \multirow[b]{2}{*}{ Likert scale } & \multicolumn{2}{|c|}{ OS 203} & \multicolumn{2}{|c|}{ OS 204} & \multicolumn{2}{|c|}{ OS 205} & \multicolumn{2}{|c|}{ OS 206} & \multirow{2}{*}{$\begin{array}{c}\text { Thiel } \\
\text { median } \\
\text { score }\end{array}$} & \multirow{2}{*}{$\begin{array}{c}\text { Formalin } \\
\text { median } \\
\text { score }\end{array}$} \\
\hline & $\begin{array}{c}\text { Thiel } \\
\text { preserved }\end{array}$ & $\begin{array}{l}\text { Formalin } \\
\text { preserved }\end{array}$ & $\begin{array}{c}\text { Thiel } \\
\text { preserved }\end{array}$ & $\begin{array}{l}\text { Formalin } \\
\text { preserved }\end{array}$ & $\begin{array}{l}\text { Thiel } \\
\text { preserved }\end{array}$ & $\begin{array}{l}\text { Formalin } \\
\text { preserved }\end{array}$ & $\begin{array}{c}\text { Thiel } \\
\text { preserved }\end{array}$ & $\begin{array}{l}\text { Formalin } \\
\text { preserved }\end{array}$ & & \\
\hline 1. Color of Skin & 1.28 & 3.52 & 1.84 & 3.39 & 2.3 & 3.45 & 1.89 & 3.86 & 1.83 & 3.56 \\
\hline 2. Texture of Skin & 1.06 & 3.2 & 1.22 & 3.38 & 1.76 & 3.35 & 1.46 & 1.46 & 1.38 & 3.48 \\
\hline $\begin{array}{l}\text { 3. Blood Vessel / } \\
\text { Nerve Integrity }\end{array}$ & 1.05 & 2.52 & 1.18 & 2.92 & 1.35 & 3.37 & 1.37 & 3.64 & 1.23 & 3.11 \\
\hline 4. Texture of Muscles & 1.07 & 2.91 & 1.19 & 3.00 & 1.46 & 3.51 & 1.44 & 3.9 & 1.29 & 3.39 \\
\hline 5. Odor & 2.51 & 3.13 & 2.40 & 3.00 & 2.60 & 2.98 & 2.86 & 3.08 & 2.59 & 3.05 \\
\hline 6. Flexibility of Joints & 1.18 & 3.29 & 1.36 & 3.6 & 2.04 & 3.73 & 1.84 & 3.97 & 1.61 & 3.65 \\
\hline $\begin{array}{l}\text { 7. Texture of } \\
\text { Internal Organs }\end{array}$ & & & 1.11 & 2.9 & 1.22 & 2.9 & 1.32 & 3.47 & 1.22 & 3.18 \\
\hline $\begin{array}{l}\text { 8. Preservation of } \\
\text { Cadavers }\end{array}$ & & & & & & & 2.36 & 2.41 & 2.36 & 2.41 \\
\hline 9. Average Scores & & & & & & & & & 1.68 & 3.22 \\
\hline
\end{tabular}

\section{OSI 203: Extremities}

OSI 204: Head and neck

OSI 205: Thorax

OSI 206: Abdomen and pelvis 
1. Presenting color of cadavers

\begin{tabular}{l|c|c|c|c|}
\hline & & & \\
\hline
\end{tabular}

3. Blood vessel/nerve integrity

\begin{tabular}{|c|c|c|c|c|}
\hline Smooth and soft & Tender but sandy and gritty & Rough, stodgy, dull & Firm, dry & Rubbery to hard \\
\hline 1 & 2 & 3 & 4 & 5 \\
\hline \multicolumn{5}{|l|}{ 4. Muscle texture } \\
\hline Smooth and soft & Tender but sandy and gritty & Rough, stodgy, dull & Firm, dry & Rubbery to hard \\
\hline
\end{tabular}

2

\begin{tabular}{l} 
5. Odor \\
$\begin{array}{c}\text { No odor } \\
\text { (can dissect for more } \\
\text { than 3 hours) }\end{array}$ \\
\hline 1
\end{tabular}

\begin{tabular}{c|c} 
Mild, tolerable odor \\
(can dissect for 2-3 hours)
\end{tabular}

Acrid but still tolerable
(can dissect for 1-2 hours)

\section{Pungent, acidic, less tolerable (can dissect less than 1 hour)}

Obnoxious, strong, foul-smelling, difficult to tolerate, causes teary eyes (difficult to dissect cont. For less than 1 hour) 5

6. Joint flexibility

6. Joint flexibility
\begin{tabular}{|c|c|c|c|c|}
\hline $\begin{array}{c}90-100 \% \text { flexion and } \\
\text { extension of joints } \\
180^{\circ}\end{array}$ & $\begin{array}{c}\text { More than } 50 \% \text { flexion } \\
\text { and extension of joints } \\
135^{\circ}\end{array}$ & $\begin{array}{c}50 \% \text { flexion and } \\
\text { extension of joints } \\
90^{\circ}\end{array}$ & $\begin{array}{c}\text { Less than } 50 \% \text { flexion } \\
\text { and extension of joints } \\
45^{\circ}\end{array}$ & $\begin{array}{c}\text { No flexion and extension } \\
4\end{array}$ \\
\hline 1 & 2 & 3 & 4 & 5 \\
\hline
\end{tabular}

7. Texture of internal organs

\begin{tabular}{c|c|c|c|c|} 
Smooth and soft & Tender but sandy and gritty & Rough, stodgy, dull & Firm, dry & Leathery to hard \\
\hline 1 & 2 & 3 & 4 & 5
\end{tabular}

8. Status of preservation

\begin{tabular}{|c|c|c|c|c|}
\hline $\begin{array}{c}\text { All organs, muscle } \\
\text { tissues, extremities } \\
\text { and blood vessels are } \\
\text { distinguishable after a year }\end{array}$ & $\begin{array}{l}\text { Organs, muscle tissues } \\
\text { and extremities are } \\
\text { distinguishable after a year }\end{array}$ & $\begin{array}{c}\text { Muscle tissues and } \\
\text { extremities still } \\
\text { distinguishable after a year }\end{array}$ & $\begin{array}{l}\text { Only extremities } \\
\text { are distinguishable }\end{array}$ & $\begin{array}{c}\text { All organs, muscle } \\
\text { tissues, extremities } \\
\text { and blood vessels are } \\
\text { destroyed after a year }\end{array}$ \\
\hline 1 & 2 & 3 & 4 & 5 \\
\hline \multicolumn{5}{|l|}{ 9. Likert Scale: Overall rating } \\
\hline $\begin{array}{l}\text { Cadaver excellent } \\
\text { for dissection }\end{array}$ & $\begin{array}{l}\text { Cadaver very good } \\
\text { for dissection }\end{array}$ & $\begin{array}{l}\text { Cadaver good } \\
\text { for dissection }\end{array}$ & $\begin{array}{l}\text { Cadaver satisfactory } \\
\text { for dissection }\end{array}$ & $\begin{array}{l}\text { Cadaver poor specimen } \\
\text { for dissection }\end{array}$ \\
\hline
\end{tabular}

Figure 1. Questionnaire on the assessment of the physical characteristics of the cadavers.

mild to acrid but tolerable, enabling students to dissect for 3 hours; 6) joints: flexion and extension could be done up to $\left.180^{\circ} ; 7\right)$ internal viscera: soft and smooth; 8) after a year of dissection: organs, muscles, tissues, and extremities were still distinguishable; and 9) over-all: the Thiel-preserved cadaver was rated good for dissection (average score was 1.68).

As indicated by the median scores, the Thiel softembalmed cadavers were evaluated higher over the formalin-preserved cadavers in terms of: skin color and texture, odor, integrity of blood vessels and nerves, texture of muscles and internal organs, joint flexibility, and status of preservation. A visual analogue scale was used to evaluate the presenting color of the cadaver and a Likert scale was used to determine the following aspects: skin texture, blood vessel and nerve integrity, odor, muscle texture, texture of internal organs, joint flexibility, preservation status, and over-all rating. (Table 1 )

On the other hand, the six formalin-preserved cadavers were assessed with the following characteristics: 1) cadaver color: medium to dark brown; 2) skin texture: rough, stodgy and dull to firm, and dry; 3 ) texture of blood vessels/nerves were rough, stodgy, and dull; 4) texture of muscles: rough, dull to firm, and dry; 5) odor was acrid but still tolerable enabling students to dissect up to 2 hours; 6) joint flexibility enabled less than $50 \%$ flexion and extension of joints up to $45^{\circ}$ only; 7) the internal viscera was assessed as rough, stodgy, 
and dull; 8) the organs, muscles, tissues, and extremities were still distinguishable after 4 courses of dissection and studying; and 9) the evaluators scored these cadavers with a rating of good specimen for dissection (average score: 3.22).

In general, both the Thiel soft-embalmed cadavers and the formalin-preserved cadavers were comparable for gross anatomy dissection. However, the Thiel soft-embalmed cadavers had the potential for research and practicing skills such as endoscopy, laryngoscopy, and intubation.

\section{Assessment of other aspects}

Figure 2 shows the questionnaire used to assess other aspects while Table 2 presents the assessment of the medical students and faculty on how they went through the dissection process; the distensibility of the structures; how they differentiated and distinguished the nerves, veins, arteries, muscles, fascial planes and sensory organs; and the feasibility of practicing laparoscopy on the cadavers.

As seen in Table 2, the formalin-preserved cadavers were rated as a better specimen for dissection with structures easily distinguishable, identified and dissected. On the other hand, the Thiel soft-embalmed cadaver rated high in terms of distensibility of structures. Although both Thiel and formalin-preserved cadavers were rated as having well-differentiated structures, the formalin-preserved cadaver rated higher in terms of the dissection process and durability of structures, especially with the sensory organs. With the Thiel soft-embalmed cadaver, the possibility of doing laparoscopy, endoscopy, and intubation was higher. Differentiation of nerves, arteries, veins, intrathoracic and intraabdominal organs, sensory organs, fascial planes, and brain was better with the formalin-preserved cadaver. In the differentiation and dissection of muscles, both the Thiel and formalin-preserved cadavers rated well.

\section{DISCUSSION}

The objective of this study was to compare the six Thiel soft-embalmed cadavers with the six formalin-preserved cadavers used by 160 medical students during their laboratory dissection in Gross Anatomy facilitated by 10 faculty members of the Department of Anatomy, UP College of

1. Dissection process?

Structure easily distinguishable, identified and dissected.

Moderate difficulty in distinguishing, identifying and dissecting structures.

Difficulty encountered in distinguishing, identifying and dissecting the structures.

2. Status of structure

$\square \quad$ Durable during dissection

$\square$ Moderately durable during dissection

$\square \quad$ Easily destroyed during dissection

3. Distensibility of structures?

Peritoneum:

$\square$ very distensible $\quad \square \quad$ moderate distensibility $\quad \square \quad$ hardly distensible

Others:

Gastrointenstinal tract and abdomen:

$\square$ very distensible $\quad \square$ moderate distensibility $\quad \square \quad$ hardly distensible

Others:

Respiratory tract and chest:

$\square$ very distensible $\quad \square$ moderate distensibility $\quad \square \quad$ hardly distensible

Others:

4. Differentiation of structures?

Nerves

Veins

Arteries

Muscles

Fascial planes

Sensory organs

Brain

Organs (intrathoracic/intraabdominal)

$\begin{array}{llll}\square & \text { Yes } & \square & \text { No } \\ \square & \text { Yes } & \square & \text { No } \\ \square & \text { Yes } & \square & \text { No } \\ \square & \text { Yes } & \square & \text { No } \\ \square & \text { Yes } & \square & \text { No } \\ \square & \text { Yes } & \square & \text { No } \\ \square & \text { Yes } & \square & \text { No } \\ \square & \text { Yes } & \square & \text { No }\end{array}$

5. Feasibility of practicing:

\begin{tabular}{|c|c|c|c|c|c|c|}
\hline scopy & $\square$ & Yes & $\square$ & No & $\square$ & Maybe but with difficulty \\
\hline Endoscopy & $\square$ & Yes & $\square$ & No & $\square$ & Maybe but with difficulty \\
\hline Intubation & $\square$ & Yes & $\square$ & No & $\square$ & Maybe but with difficulty \\
\hline
\end{tabular}

Others:

Figure 2. Questionnaire on the assessment of other aspects. 
Table 2. Assessment of Other Aspects

1. Dissection process

- Structure easily distinguishable, identified and dissected.

Moderate difficulty in distinguishing, identifying and dissecting structures.

$\begin{array}{lccc}33 / 165 & 20 \% & 68 / 165 & 41.2 \% \\ 88 / 165 & 53.3 \% & 84 / 165 & 50.9 \%\end{array}$

- Difficulty encountered in distinguishing, identifying and dissecting the structures.

2. Status of structure

- Durable during dissection

- Moderately durable during dissection

$44 / 165$

$26.7 \%$

$7.9 \%$

- Easily destroyed during dissection

$\begin{array}{llcc}35 / 166 & 21.1 \% & 94 / 165 & 57 \% \\ 72 / 166 & 43.4 \% & 62 / 165 & 37.6 \% \\ 59 / 166 & 35.5 \% & 9 / 165 & 5.4 \%\end{array}$

3. Distensibility of structure

Peritonuem

- Very distensible

- Moderate distensibility

- Hardly distensible

Gastrointestinal tract and abdomen

- Very distensible

- Moderate distensibility

- Hardly distensible

Respiratory tract and chest

- Very distensible

- Moderate distensibility

- Hardly distensible

4. Differentiation of structure
A. Nerve
Yes
No

B. Veins

Yes

No

C. Arteries

Yes

No

D. Muscles

Yes

No

E. Facial planes

Yes

No

F. Sensory organs

Yes

No

G. Brain

Yes

No

$\begin{array}{cccc}123 / 166 & 74.1 \% & 13 / 165 & 7.9 \% \\ 37 / 166 & 22.3 \% & 112 / 165 & 67.9 \% \\ 6 / 166 & 36 \% & 40 / 165 & 24.2 \% \\ & & & \\ 136 / 166 & 81.9 \% & 18 / 165 & 10.9 \% \\ 26 / 166 & 15.7 \% & 116 / 165 & 70.3 \% \\ 4 / 126 & 2.4 \% & 31 / 165 & 18.8 \% \\ & & & \\ 129 / 166 & 77.7 \% & 16 / 165 & 9.7 \% \\ 32 / 166 & 19.3 \% & 106 / 165 & 64.2 \% \\ 5 / 166 & 3 \% & 43 / 165 & 26.1 \%\end{array}$

H. Organs (intrathoracic/intraabdominal) Yes

\begin{tabular}{cccc}
$89 / 166$ & $53.6 \%$ & $145 / 165$ & $87.9 \%$ \\
$76 / 166$ & $46.4 \%$ & $20 / 165$ & $12.1 \%$ \\
& & & \\
$82 / 166$ & $49.4 \%$ & $140 / 164$ & $85.4 \%$ \\
$84 / 166$ & $50.6 \%$ & $24 / 164$ & $14.6 \%$ \\
& & & \\
$99 / 166$ & $59.6 \%$ & $146 / 165$ & $88.5 \%$ \\
$67 / 166$ & $40.4 \%$ & $19 / 165$ & $11.5 \%$ \\
& & & \\
$149 / 166$ & $89.8 \%$ & $152 / 165$ & $92.1 \%$ \\
$17 / 166$ & $10.2 \%$ & $13 / 165$ & $7.9 \%$ \\
& & & \\
$95 / 166$ & $57.2 \%$ & $129 / 165$ & $78.2 \%$ \\
$71 / 166$ & $42.8 \%$ & $36 / 165$ & $21.8 \%$ \\
& & & \\
$117 / 166$ & $70.5 \%$ & $147 / 165$ & $89.1 \%$ \\
$49 / 166$ & $29.5 \%$ & $18 / 165$ & $10.9 \%$ \\
& & & \\
$54 / 166$ & $32.5 \%$ & $161 / 165$ & $97.6 \%$ \\
$112 / 166$ & $67.5 \%$ & $4 / 165$ & $2.4 \%$ \\
$120 / 166$ & $72.3 \%$ & $159 / 165$ & $96.4 \%$ \\
$46 / 166$ & $27.7 \%$ & $6 / 165$ & $3.6 \%$ \\
\hline
\end{tabular}

5. Feasibility of practicing:

A. Laparoscopy

Yes

No

Maybe but with difficulty

B. Endoscopy

Yes

No

Maybe but with difficulty

C. Intubation

Yes

No

Maybe but with difficulty

$\begin{array}{cccc}93 / 160 & 58.1 \% & 22 / 159 & 13.8 \% \\ 9 / 160 & 5.6 \% & 70 / 159 & 44 \% \\ 58 / 160 & 36.3 \% & 67 / 159 & 42.2 \% \\ & & & \\ 99 / 160 & 61.9 \% & 20 / 159 & 12.6 \% \\ 9 / 160 & 5.6 \% & 69 / 159 & 43.4 \% \\ 52 / 160 & 32.5 \% & 70 / 169 & 44 \% \\ & & & \\ 111 / 162 & 68.5 \% & 24 / 161 & 14.9 \% \\ 5 / 162 & 3.1 \% & 71 / 161 & 44.1 \% \\ 46 / 162 & 28.4 \% & 66 / 161 & 41 \%\end{array}$


Medicine. The dissection of these twelve cadavers was done during the laboratory period of these courses: OSI 203, OSI 204, OSI 205, and OSI 206. The whole bodies and faces of the twelve cadavers were dissected and studied for a period of 8 months. According to Kerckaert, et al (2008), cadavers fixed by conventional procedures using formalin for conservation, are of limited use for practical surgical courses due to the profound changes of color, strength, and fragility of organs and tissues. The new Thiel embalming technique is based on the use of 4-chloro-3-methylinphenol, various salts for fixation, boric acid for disinfecting and ethylene glycol for preservation of tissue plasticity, while the concentration of formalin is kept to the strict minimum (0.8\%).

There is no denying that dissection and training with the use of cadavers is a common, acceptable, and excellent teaching tool. Several publications have described the Thiel soft-embalmed cadavers as having exceptional benefits, particularly for anatomical investigations and teaching purposes $8,9,10,16,22,23$; Reasons noted are: cadavers preserved with the Thiel Method have no detectable odor; lifelike flexibility of body parts; excellent color and texture preservation of muscle, viscera and vasculature; and superior antimicrobial preservation properties. Because of the more life-like texture and color of structures, students' dissections are of high quality, improving learning in the laboratory. Also, appreciation of the actions of muscles at joints, especially in the extremities, is facilitated by the flexibility of the Thiel soft-embalmed cadavers ${ }^{8,22}$. Aside from evaluating the physical characteristics of the Thiel softembalmed cadavers compared to the formalin-preserved ones, other aspects were also assessed such as the ease of the dissection process; the distensibility, differentiation and durability of the different structures such as blood vessels, nerves, fascial planes and sensory organs; and the perception on the feasibility of practicing intubation and laparoscopic procedures on the Thiel cadavers.

The Thiel cadavers used in this study are similar to that described by Roop ${ }^{22}$ which utilized the soft embalming protocol employed at the Virginia State Anatomical Program in Richmond, Virginia, USA. The major difference from the other Thiel cadavers $8,9,10,16,18,21,23$ is the elimination of the body being submerged in a tank with embalming fluid for at least 4-6 months. Despite new techniques in embalming, the search for the optimal method which provides life-like conditions, long term usage and costeffectiveness, is still on-going. However, several publications have described Thiel's method as having exceptional benefits particularly for surgical and anatomical investigations, as well as teaching purposes $3,8,9,10,21,23$. The technique was initially developed by Thiel at the Institute of Anatomy, Medical University Graz, Austria in 1992 $2^{10,22}$. As claimed, it offers excellent cadaver conservation, spectacular flexibility, natural colors, and limited respiratory and eye irritation for dissectors and handlers. More recently, various studies have been done using the Thiel soft-embalmed cadavers simulating several procedures in several fields: bronchoscopy and cricothyrotomy ${ }^{10}$; MR-guided focused Ultrasound Surgery ${ }^{9}$; biomechanical investigations ${ }^{11}$; endoscopic sinus surgery; oral surgery and implantology ${ }^{23}$; urology ${ }^{9}$; laparoscopy ${ }^{12}$; anaesthesiology and regional blocks; ${ }^{8,10}$ and other procedures.

This study is the first in the Philippines since the University of the Philippines, Department of Anatomy is the first to employ the use of Thiel-preserved cadavers for Gross Anatomy dissection among first year students.

\section{Comments on the formalin-preserved cadavers}

Positive comments included the following: fit for students of anatomy since most structures and organs retain their shape and form; viscera are easily identifiable; and anatomical landmarks are prominent

Negative comments included the following: the preservation produces tough and durable structures making dissection tedious; skin, muscles, and fascia were difficult to distinguish; the hardened structures of the head and neck area made dissection hard and tiresome, demanding too much effort and endurance since the smell is pungent and penetrating; and molds were formed at the end of the school year and the smell became foul and rotten.

\section{Comments on the Thiel soft-embalmed cadavers}

Positive comments included the following: very lifelike; structures looked so real; excellent for musculo-skeletal dissection; tendons were easily appreciated; intubation and lung inflation was excellent and looked very real; ideal for endoscopy and laparoscopy; scent was tolerable and better compared to the formalin; and dissecting it was a great learning experience.

Negative comments included the following: internal organs were very soft, floppy, extremely distensible becoming delicate to handle and dissect; nerves, veins, and arteries were too soft and easily destroyed; eyes became shrunken; fluid accumulated in the heart and lungs; brain was mushy and poorly preserved; and the smell was fish-like at the end of the semester.

It is understood that no cadaver model can completely match a live patient in all aspects. Since cadavers maybe realistic in some aspects, care must be taken in determining the extent to which any training experience translates to the clinical equivalent ${ }^{7}$.

Limited work so far has been done to validate Thiel soft-embalmed cadavers for different applications. Most studies are qualitative, relying on feedback from practitioners and trainees ${ }^{7,11}$. Some studies compare different cadaver models but do not directly compare these with live patients ${ }^{7}$. A full understanding of the different aspects and properties of tissues related to the procedure for study is needed to provide real insight into the strengths and limitations of the Thiel cadaver model and to underpin their use in the various fields of medicine. 


\section{CONCLUSION}

The Thiel soft-embalmed cadavers which were utilized for Gross Anatomy dissection in our institution offer a combination of high fidelity (life-like appearance, tissue quality, and easy handling) and longevity. While they are not yet a universal replacement for either the formalin-embalmed or fresh-frozen cadavers, there is much overlap in relation to the areas of usage. Their real strength maybe borne in applications where flexibility and durability are required, offering new areas for teaching, research, and training.

\section{Statement of Authorship}

All authors approved the final version submitted.

\section{Author Disclosure}

All authors declared no conflict of interest.

\section{Funding Source}

This paper was funded by the Department of Science and Technology - Philippine Council for Health Research and Development (DOST-PCHRD).

\section{REFERENCES}

1. Balcombe J. The use of animals in higher education: problems, alternatives, and recommendations (ed 1). Washington. The Humane Society Press; 2000. pp 34-35

2. Benkhadra M, Faust A, Ladoive S. Comparison of Fresh and Thiel's embalmed cadavers according to the suitability for ultrasoundguided regional anesthesia of the cervical region. Surg Radiol Anat. 2009;31:531-3.

3. Brenner E. Human body preservation - old and new techniques. Journal of Anatomy. 2014; (224), pp 316-44

4. Carpenter LG, Piermattei DL, Orton EC, et. al. A comparison of surgical training with live anesthetized dogs and cadavers. Vet Surg. 1991;20:373-8.

5. Cuddy MM, Swanson DB, Drake RL, Pawlina W. Changes in anatomy instruction and USMLE performance: empirical evidence on the absence of a relationship. Anat Sci Educ. 2013;6(1):3-10. doi: 10.1002/ase.1343.

6. Da Silva RMG, Matera JM, Ribiero AACM. Preservation of cadavers for surgical training techniques. Vet Surg. 2004;33: 606-8.

7. Duffee N. Alternative training methods I: proceedings of the 1998 LAWTE meeting. Lab Anim. 1999;28:32-6.

8. Eisma R, Lamb C, Soames R.W. From formalin to thiel embalming. What changes? One anatomy department's experiences. Clinical Anatomy. 2015;26:564-71.

9. Eisma R, Wilkinson T. From Silent Teachers to Models. PLOS Biology 2014;12(10): e1001971.doi:10,1371/journal,pbio.1001971.
10. Feigl G, Benkhadr, M,Lenfant F, Trouilloud P,Anderhuber F, Bonniaud P, Fasel JHD, Nemetz W. Bronchoscopy and Cricothyroitomy results from cadavers embalmed with Thiel's method compared to other embalming methods and living subjects. Acta Medico-Biotechnica. 2000; 1:25-36.

11. Fessel G, Frey K, Schweizer A, Calcagni M, Ullrich D, Snedeker J.G. Suitability of Thiel embalmed tendons for biomechanical investigation. Ann Anat. 2011;193(3):237-41. doi: 10.1016/j.aanat.2011.03.007.

12. Giger U, Fresard I, Hafliger A, Bergmann M, Krahenbuhl L,. Laparoscopic training on Thiel human cadavers: a model to teach advances laparoscopic procedures. Surg Endosc. 2008;22(4):901-6

13. Groscurth P, Eggli P, Kapfhammer J, Rager G, Hornung JP, Fasel JD. Gross Anatomy in the surgical curriculum in Switzerland: improved cadaver preservation, anatomical models and courses development. Anat Rec. 2001;265(6):254-6

14. Grullo PER, Hernando HCT, Carillo RJDC, Villacorta PRF, Hernandez JG, Lopa RAB, et al. Surgical Simulation of Endoscopic Sinus Surgery using Thiel Soft-Embalmed Human Cadaver. Acta Med Philipp. 2017;51(1):24-7

15. Hadie SNH, Asma H, Zul IMI, et. al. The need to have a valid and reliable tool to measure the anatomy education environment. Education in Medicine Journal. 2013;5 (3):e81-e85. DOI: 10.5959/eimj.v5i3.148.

16. Hammer N, Löffler S, Bechmann I, Steinke H, Hädrich C, Feja C. Comparison of modified thiel embalming and ethanol-glycerin fixation in an anatomy environment: Potentials and limitations of two complementary techniques. Anat Sci Educ. 2015;8(1):74-85. doi: 10.1002/ase.1450.

17. Hoshino K, Bradbury SA.. An improved embalming procedure for long-lasting preservation of the cadaver for anatomical study. Acta Anat. 1978;101:97-103.

18. Jaung R, Cook P, Blyth P. A comparison of embalming fluids for use in surgical workshops. Clin Anat. 2011;24(2):155-61. doi: 10.1002/ ca. 21118 .

19. Kerckaert I, Hoof TV, Pattyn P, Herde K. Anatomy teaching. Anatomy.2008;2:28-33.

20. Kotzé SH, Mole CG, Greyling LM. The translucent cadavers: an evaluation of the use of full body digital $\mathrm{x}$-ray images and drawing in surface anatomy education. Anat Sci Educ. 2012;5(5):287-94. doi: 10.1002/ase.1277.

21. Lin SC, Hsu J, Fan VY. Silent virtuous teachers: anatomical dissection in Taiwan. BMJ. 2009;339:b5001. doi: 10.1136/bmj.b5001.

22. Roop, Jason. Life after death. Style Weekly. 2014;32:36;12-6.

23. Sangchay N. The soft cadaver (Thiel's method): The new type of cadaver of Department of Anatomy, Siriraj Hospital. Siriraj Medical Journal. 2014;66;S228-S31.

24. Schweisthal MIR. The use of fresh specimens in the gross anatomy laboratory. Anat Rec. 1968;160:496.

25. Tschernezky W. Restoration of the softness and flexibility of cadavers preserved in formalin. Acta Anat. 1984;118:59.

26. Virginia State Anatomical Program Protocol. Virginia Department of Health, Richmond, Virginia, USA. 2015.

27. Code of Sanitation of the Philippines Chapter 21: Implementation of Rules and Regulations on Disposal of Dead Persons. PD 856 (1997). 